\title{
TAX EFFECTS, SEARCH UNEMPLOYMENT, AND THE CHOICE OF EDUCATIONAL TYPE
}

\author{
ANNETTE ALSTADSÆTER \\ ANN-SOFIE KOLM \\ BIRTHE LARSEN
}

CESIFO WORKING PAPER NO. 1622

CATEGORY 1: Public FinANCE

DECEMBER 2005

An electronic version of the paper may be downloaded

- from the SSRN website:

wWw.SSRN.com

- from the CESifo website: www.CESifo-group.de 


\title{
TAX EFFECTS, SEARCH UNEMPLOYMENT, AND THE CHOICE OF EDUCATIONAL TYPE
}

\begin{abstract}
This paper examines the effect of taxes on the individuals' choices of educational direction, and thus on the economy's skill composition. A proportional labour income tax induces too many workers with high innate ability to choose an educational type with high consumption value and low effort costs. This increases the skill mismatch and aggregate unemployment in the economy. The government can correct for this distortion by use of differentiated tuition fees or tax rates.
\end{abstract}

JEL Code: J64, J68, H21, H24.

Keywords: unemployment, matching, education, optimal taxation, tuition fees.

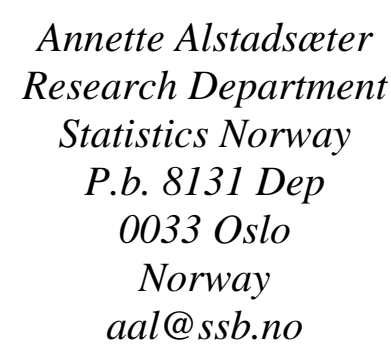

\author{
Ann-Sofie Kolm \\ Department of Economics \\ Stockholm University \\ 10691 Stockholm \\ Sweden \\ ann-sofie.kolm@ne.su.se
}

\author{
Birthe Larsen \\ Copenhagen Business School \\ Department of Economics \\ Solbjerg Plads 3 \\ 2000 Copenhagen \\ Denmark \\ bl.eco@cbs.dk
}

November 15, 2005.

This paper has benefited from comments by Rolf Aaberge, John Dagsvik, Erling Holmøy, Pascalis Raimondos-Møller, Agnar Sandmo, and Knut R. Wangen, as well as conference participants at the Norwegian-German Seminar on Public Economics in GarmischPartenkirchen, September 2005. 


\section{Introduction}

Recently, much attention has been given to the fact that unemployment is higher for low skilled workers than for highly educated workers. However, little focus has been given to the fact that different employment perspectives exist for different groups of highly educated workers. As the educational choice of today's young generation determines the skill composition and hence the production possibilities of tomorrow's labour force, which type of higher education individuals choose becomes an important issue. The increasing competition for the location of production to low-cost countries further actualizes industrialized countries' focus on high-skilled labor and its composition. However, although the skill combination is essential for a country's economic performance, governments encourage individuals to get higher education while to a great extent ignoring which type of higher education they acquire.

This paper examines the link between a country's tax system and the skill composition of the work force, and shows that income taxes might increase the skill mismatch in the society and increase total unemployment. The presence of labor income taxes induces more high-ability individuals to choose an educational type with high consumption value. Correspondingly, fewer high-ability individuals choose to acquire the educational type that requires more effort than in the absence of taxes.

By introducing the concept of human capital, Schultz (1960) and Becker (1964) introduced a shift in the economic literature into considering education as an investment that yields higher wages later in life. Prior to this, education was considered a cultural good, and there was emphasis on the non-pecuniary returns to a job or an education, as seen in Marshall (1920). The recent literature on the economics of education to a great extent ignores non-pecuniary returns and costs when modeling the educational decision.

Different educational directions are associated with different pecuniary and non-pecuniary costs and returns. Wage levels vary substantially across occupations and sectors, as do unemployment rates. The individual's innate ability level determines both the effort required to complete a specific education and the wage return to this particular education. His consumption value of an educational type depends on the individual specific preferences. The consumption value of education, among other things, consists of the joy of learning new things, meeting new people, moving to a new city, and enjoying life as a student, in addition to the increased status in society that 
often comes with studying in particular fields. In addition, education also brings a consumption value in the future, since it qualifies the individual to work in his preferred profession. Non-pecuniary returns can be important motivations for the individual's educational choice. Alstadsæter (2004) estimates that Norwegian teacher's college graduates' willingness to pay for the consumption value of this educational type was at least $38 \%$ of the present value of their potential lifetime income. Also, Walker and Zhu (2003) report a negative wage return to an arts degree in the UK, while the positive wage return to an engineering degree is substantial. This could mean that art graduates have a large positive consumption value of this educational type, such that they are willing to forego earnings by not choosing engineering. These foregone earnings are then the price on the consumption value of an arts degree. But it is also possible that the effort costs of completing an engineering degree would have been so high for the arts major that they for that reason decide against it. ${ }^{1}$

In the economic literature, surprisingly little attention has been given to the question of how the tax system affects the individual's choice of educational direction, and even less attention has been given to the consequences for a country's skill composition. More work has been done on the effects of taxes on the level of educational attainment when education is a homogenous investment alternative; Boskin (1975), Heckman (1976), Driffil and Rosen (1983), and Nielsen and Sørensen (1997). ${ }^{2}$

Alstadsæter (2003) was the first to explicitly analyze the tax effects on the type of educational attainment, and she argues that a higher wage tax might induce students to choose more of the educational type with high consumption value. The model was set in partial equilibrium. MalchowMøller and Skaksen (2003) expand the framework set out in Alstadsaeter (2003). They consider identical workers who decide on on how to allocate their time between productive and non-productive education and leisure. They show that it can be optimal to have regressive labour taxation and high uniform tuition fees.

\footnotetext{
${ }^{1}$ As both ability and preferences are important in the educational choice, some individuals with low effort costs when acquiring engineering may also have higher consumption value from this educational type. These individuals then enjoy both a high wage return and a high non-pecuniary return to their chosen type of education.

${ }^{2}$ Much work has also been done on tax effects on occupational choice, in particular regarding the choice between being an entrepreneur or employee; Pestieu and Possen (1991), Parker (1996), Bruce (2000), and Gentry and Hubbard (2000).
} 
Also the present paper expands on Alstadsæter (2003) and develops a simple equilibrium model that captures some important dimensions of the educational choice when the level of education is given. Education is both investment and consumption. Individuals with heterogenous ability levels choose among two educational types. The first type yields a positive consumption value, but has long expected unemployment spells and a modest wage return. The second type yields a higher wage return, shorter expected unemployment spells, but requires an ability-dependent effort to complete. Wages are set through wage bargains and unemployment features in equilibrium. The wage returns net of taxes and the expected unemployment spells are thus endogenously determined and are important factors when individuals decide on their educational direction.

Proportional income taxes increase the importance of non-pecuniary returns and costs for the choice of educational direction by reducing the importance of expected wage returns. This is because the consumption value and effort cost are tax exempt returns and costs to education. We show that taxes distort the individuals' educational choices, such that too few highability workers choose the educational direction that requires effort, and too many high-ability workers choose the educational direction associated with a positive consumption value. This, in turn, implies that too many individuals choose an educational type associate with long expected unemployment spells. The result is that unemployment is higher than it would have been if individuals chose the socially optimal educational portfolio. The distortion can however be corrected for either by imposing higher tuition fees on educational types with high consumption values or by subsidizing educational types that require high effort to complete. Differentiated tax rates can also be used to correct for this distortion.

The paper is organized as follows. In section 2 the two-sector model employing two different educational types is described and we consider the impact on educational direction and total unemployment from proportional labour taxation. Section 3 considers welfare, concluding that proportional taxation distorts the educational decision and thus reduces welfare. The following section evaluates whether differentiated taxes may be used to correct for this distortion, and we consider the impact of tax differentiation on educational direction and total unemployment. In Section 5 we examine the same issues by extending the model with differentiated tuition fees and subsidies. A discussion is provided in Section 6. Finally we conclude in section 7. 


\section{The model}

Consider an economy where workers may choose to acquire two different types of higher education of the same duration, type $c$ and type $e$. It is not necessarily the case that the two types of education provide workers with different productivities. However, educational type $c$ brings the worker a higher consumption value than educational type $e$. For simplicity and without loss of generality, we introduce this effect in our model by letting the consumption value of acquiring education $e$ be zero and the consumption value of education $c$ be positive. On the other hand, education $e$ is associated with higher educational effort costs than education $c$. Again, without loss of generality, we introduce this effect by letting educational costs associated with education $c$ be zero and the educational costs associated with sector $e$ be positive.

Workers differ in ability, $a$, which is known to the individual and is, without loss of generality, assumed to be uniformly distributed across individuals. Educational effort costs, $\kappa(a)$, are decreasing in ability, $\kappa^{\prime}(a)<0$. That is, the higher innate ability, the less effort is required in order to attain education of type $e$. The consumption value of type $c$ education is the same for all individuals. ${ }^{3}$ The choice of educational type is discrete, such that individuals choose to acquire either education of type $c$ or education of type $e$.

There are two sectors in the economy, where sector $c$ employs workers with educational type $c$ and sector $e$ employs workers with educational type $e$. The two sectors differ in the sense that sector $e$ provides workers with better employment perspectives. The better employment perspectives both include high wages and low unemployment probabilities. As both those variables are endogenously determined in the model, we establish these relative values by either higher productivity in sector $e$ or lower separation rates from employment in sector $e$. This corresponds to higher expected pecuniary payoffs in sector $e$, as wages are higher and workers will spend more time in

\footnotetext{
${ }^{3}$ Note that we could alternatively assume that workers differ with respect to preferences over the consumption value of education $c$. With the normalization of letting the consumption value of educational type $e$ be zero, then $a$ would denote different preferences for the consumption value of educational type $c$. The function $\kappa(a)$ then captures utility gain of educational type $c$ where $\kappa^{\prime}(a)<0$ captures that utility falls with the preference parameter $a$. That is, workers with high $a$ have a smaller consumption value of educational type $c$ than individuals with a low $a$. The same results as we present in the paper below would then materialize.
} 
employment during a working life.

We now proceed by setting up a two-sector matching equilibrium model along the lines of Pissarides (2000) that captures the individual's educational decision described above.

\subsection{Workers and firms}

Unemployed workers search for jobs in sector $c$ or sector $e$ depending on which type of education they acquire. The matching process in each sector is captured by a concave, constant-returns-to-scale matching function,

$$
H_{j}=h\left(v_{j}, u_{j}\right), \quad j=c, e,
$$

where $H_{j}$ is the matching rate, $v_{j}$ is the vacancy rate, and $u_{j}$ is the unemployment rate. The rates are defined as the numbers relatively to the labour force of the specific type. The transition rate into employment for a worker of type $j$ is given by $\lambda_{j}=H_{j} / u_{j}=h\left(\theta_{j}, 1\right)=\lambda\left(\theta_{j}\right)$, where $\theta_{j}=\frac{v_{j}}{u_{j}}$, captures sectorial labour market tightness. The rate at which vacant jobs become filled is $q_{j}=H_{j} / v_{j}=h\left(1,1 / \theta_{j}\right)=q\left(\theta_{j}\right)$. Consequently, we have $\lambda\left(\theta_{j}\right)=\theta_{j} q\left(\theta_{j}\right)$, where $\lambda^{\prime}\left(\theta_{j}\right)=q\left(\theta_{j}\right)\left(1-\eta\left(\theta_{j}\right)\right)>0$ and $q^{\prime}\left(\theta_{j}\right)<0$. $\eta \in(0,1)$ is the elasticity of the expected duration of a vacancy with respect to $\theta_{j}$, i.e., $\eta\left(\theta_{j}\right)=q^{\prime}(.) \theta_{j} / q($.$) . Higher labour market tightness in a sec-$ tor, $\theta_{j}$, increases the likelihood of a worker in that sector finding a job, but reduces the likelihood for a firm finding a worker.

Workers who choose to acquire education of type $c$ enjoy a positive consumption value, where $d$ is the imputed monetary value of this consumption value. ${ }^{4}$

Let $U_{c}$ and $E_{c}$ denote the expected present values of unemployment and employment for a worker who has acquired type $c$ education. The value

\footnotetext{
${ }^{4}$ As discussed in the introduction, this non-pecuniary returns could include returns while in education such as the joy of learning new things, meeting new people, moving to a new city, and enjoying life as a student, but it could also include returns received after the education is finished such as status in society, having a fun job etc. Both these interpretations are valid in our model although we, for simplicity, impute the consumption value of type $c$ education as a flow value in equations (1) and (2) below. The assumption enables us to use a model without having workers continuously being born and dying. Such a model would, however, generate the same qualitative results. The same holds for the interpretations of the effort costs in equations (3) and (4) below.
} 
functions for a worker $i$ with type $c$ education who is paid $w_{c i}$ then reads:

$$
\begin{aligned}
r E_{c i} & =R+w_{c i}(1-t)-s_{c}\left(E_{c i}-U_{c}\right)+d, \\
r U_{c} & =R+\lambda_{c}\left(E_{c}-U_{c}\right)+d
\end{aligned}
$$

where $r$ is the discount rate, $s_{c}$ is the exogenous separation rate in sector $c$, and $R$ is a lump sum transfer that all individuals receive from the government which reflects that the government has some positive revenue requirements. The parameter $t$ is the proportional income tax. $r U_{c}$ is the average expected return to an unemployed type $c$ worker's human capital during job search. The unemployed worker receives the lump-sum transfer and the consumption value of education. However, the person also has a unit probability of becoming employed, $\lambda_{c}$, and thus to increase his or her value by $\left(E_{c}-U_{c}\right)$. Equation (1) can be given a similar interpretation. In addition to the instantaneous returns to employment given by the after tax wage, lump-sum transfer and the consumption value of education, an employed worker faces a risk of loosing his or her job, $s_{c}$, and thus to experience a loss of $\left(E_{c}-U_{c}\right)$.

Workers who choose to acquire education of type $e$ face effort costs which depend negatively on their ability. The imputed monetary value of the individual effort cost is denoted $\kappa(a)$, where $a$ is the worker's ability, $a \in[0,1]$ and $\kappa^{\prime}(a)<0$. Let $U_{e}$ and $E_{e}$ denote the expected present values of unemployment and employment. The value functions for a worker with ability $a$ and type $e$ education who is paid $w_{e i}$ then reads:

$$
\begin{aligned}
r E_{e i} & =R+w_{e i}(1-t)+s_{e}\left(U_{e i}-E_{e i}\right)-\kappa(a), \\
r U_{e} & =R+\lambda_{e}\left(E_{e}-U_{e}\right)-\kappa(a),
\end{aligned}
$$

where $s_{e}$ is the exogenous separation rate in sector $e$. It is straight forward to interpret these equations in terms of asset equations in a similar fashion as for type $c$ workers.

Firms opening vacancies in sector $j$ employ workers with the marginal productivity $y_{j}$. Their time unit probability of filling a vacancy is $q_{j}$. Let $J_{j}$ and $V_{j}$ represent the expected present values of an occupied job and a vacant job for firms in sector $j$. The arbitrage equations for a specific job paying the wage $w_{j i}$ and a vacant job in the sector $j$ are:

$$
\begin{aligned}
r J_{j i} & =y_{j}-w_{j i}(1+z)+s_{j}\left(V_{j}-J_{j i}\right), \quad j=c, e, \\
r V_{j} & =q_{j}\left(J_{j}-V_{j}\right)-k, \quad j=c, e
\end{aligned}
$$


where $z$ is the payroll tax rate and $k$ denotes vacancy costs. As a filled job is an asset owned by the firm, equation (5) captures the rate of return to this asset. The rate of return is the instantaneous profit made from having this job being filled, but the firms also face a risk of loosing its worker, $s_{j}$, and thus to face the loss $\left(J_{j}-V_{j}\right)$. For a vacant job the rate of return is given by the vacancy cost, $k$, but also the unit probability of finding a worker, $q_{j}$, so to fill this vacancy and make a capital gain of $\left(J_{j}-V_{j}\right)$.

Individual wages, $w_{c i}$ and $w_{e i}$, are determined by individual Nash Bargaining. More specifically we solve $\operatorname{Max}_{w_{j i}}\left(E_{j i}-U_{j}\right)^{\beta}\left(J_{j i}-V_{j}\right)^{1-\beta}, j=c, e$, where $\beta$ denotes the workers' bargaining power. The first order conditions can be written as $\beta /(1-\beta)(1 / \phi) J_{j}=E_{j}-U_{j}$, where

$$
\phi \equiv \frac{1+z}{1-t}
$$

is the tax wedge, and where we have imposed symmetry and the free entry condition, $V_{j}=0, j=c, e$.

We can solve for the bargained wage by using this first order condition and equations (1)-(6), assuming free entry, that is $V_{j}=0$, and a symmetric equilibrium. The bargained wage is given by:

$$
\omega_{j}=w_{j}(1+z)=\beta\left(y_{j}+\theta_{j} k\right), \quad j=c, e,
$$

where $\omega_{j}$ is the producer wage in sector $j$. The solution for labour market tightness in sector $j$, can be derived from equations (5) and (6), using the free entry condition and the expression for $\omega_{j}$ :

$$
\frac{k\left(r+s_{j}\right)}{q\left(\theta_{j}\right)}=(1-\beta) y_{j}-\beta \theta_{j} k, \quad j=c, e .
$$

The sectorial producer wage then follows residually from equation (7). We assume that $y_{e} \geq y_{c}$ and $s_{c} \geq s_{e}$ with a strict inequality in at least one of the two expressions. From equation (7) and (8) we obtain the result that labour market tightness and producer wages are higher in sector $e, \theta_{e}>\theta_{c}$ and $\omega_{e}>\omega_{c}$. Furthermore, as payroll taxes and income taxes are equal in the two sectors, then consumer wages, $w_{j}$ must also be higher in sector $e$ than in sector $c, w_{e}(1-t)>w_{c}(1-t)$.

Steady state unemployment rates for the two types of workers are derived by considering the flows into and out of unemployment, that is $s_{j}\left(1-u_{j}\right)=$ 
$\lambda_{j} u_{j}$ giving

$$
u_{j}=\frac{s_{j}}{s_{j}+\lambda_{j}}, j=c, e .
$$

Hence, as a higher labour market tightness in sector $e$ corresponds to a higher transition rate for workers searching for employment in sector $e$, $\lambda_{e}>\lambda_{c}$, and $s_{c} \geq s_{e}$, then the unemployment rate is higher in sector $c$ than in sector $e$., i.e., $u_{e}<u_{c}$.

\subsection{Education and unemployment}

When a worker decides on which type of education to acquire, he or she compares the value as a type $c$ worker to the value as a type $e$ worker. The workers could compare the value of unemployment, employment, or a weighted average of both, of being a type $c$ worker to the equivalent value of being a type $e$ worker. To simplify the exposition, we will assume that the discount rate approaches zero. This assumption is of no importance for the results, but it is convenient as it does not matter whether we compare the value of unemployment, employment or a weighted average of both, between the two types of education.

Workers carefully consider the consequences of their choice of educational direction in a number of dimensions. For example, they compare the expected unemployment spells of the two types of educations. Moreover, they account for differences in the after tax wage of the two types of educational directions. In addition, they account for that type $c$ education is associated with a positive consumption value whereas education of type $e$ requires effort. As ability differs across individuals, educational costs associated with type $e$ education differs. This implies that workers with low ability may find it too costly in terms of effort to acquire education of type $e$.

The marginal worker has an ability level, $\hat{a}$, which makes him or her just indifferent between acquiring education of type $c$ and education of type $e$. We can write the condition determining the ability level of the marginal worker $\mathrm{as}^{5}$ :

$$
r U_{c}=r U_{e}(\hat{a}) .
$$

Using the arbitrage equations, (1)-(4) we can write this condition as

$$
\left(1-u_{c}\right) w_{c}(1-t)+d=\left(1-u_{e}\right) w_{e}(1-t)-\kappa(\hat{a}),
$$

\footnotetext{
${ }^{5}$ Recall that $r U_{j}=r E_{j}=A r U_{j}+(1-A) r E_{j}$ when the discount rate approaches zero, for $j=c, e$ and the weight $A$.
} 
The lower unemployment rate, and the higher take home pay, in sector $e$ induces individuals to choose type $e$ education rather than type $c$ education. On the other hand, since type $c$ education holds a direct consumption value and type $e$ education requires effort, this induces individuals to choose type $c$ education.

Alternatively to the above approach, we can use equations (2) and (4) in equation (10) and then the first order conditions for Nash Bargaining following by equation (6) after imposing the free entry condition, $V_{j}=0, j=$ $c, e$. The condition determining the ability of the marginal worker may then be written as

$$
\kappa(\hat{a})=\frac{\beta}{1-\beta} \frac{k}{\phi}\left(\theta_{e}-\theta_{c}\right)-d .
$$

This equation gives $\hat{a}$ as a function of the endogenous variables $\theta_{c}$ and $\theta_{e}$. As $\theta_{c}$ and $\theta_{e}$ are determined in equation (8), where $\theta_{e}-\theta_{c}>0, \hat{a}$ and $1-\hat{a}$ resolve the number of workers acquiring type $c$ education and the number of workers acquiring education of type $e$. Workers with $a \leq \hat{a}$, choose to acquire education of type $c$ whereas workers with $a>\hat{a}$ acquire education of type $e$. From equation (12) it is clear that the individual's choice of educational type is independent of whether taxes are levied on firms or on workers. Any reallocation of the tax burden across the individual and the firm is counteracted by adjustments in the pre-tax wage set in the bargains.

Conducting comparative statics on the allocation of workers across the two types of education reveals that:

Proposition 1 Increased taxation induces some workers to reallocate their choice of educational direction from type e towards type $c$, that is $\partial \hat{a} / \partial \phi>0$.

Proof. Differentiating equation (12) with respect to $\hat{a}$ and $\phi$ gives the result immediately as $\theta_{j}, j=c, e$ are unaffected by a change in $\phi$ and $\kappa^{\prime}(\hat{a})<0$.

Higher income taxes reduce the monetary return to both educational types, while both the consumption value of type $c$ education and the effort cost of type $e$ education are unchanged. As the monetary return to the educational types are reduced through the increased tax, non-monetary returns become more important for the educational decision. It thus follows intuitively that some workers will reallocate their choice of educational direction towards the type of education which is associated with a positive consumption value and away from the type of education which is associated with 
effort costs. It is simply no longer worth while for these individual's to acquire type $e$ education as the expected net of taxes wage premium no longer fully compensates their effort costs.

Total unemployment is given by

$$
U^{T O T}=\hat{a} u_{c}+(1-\hat{a}) u_{e} .
$$

We have the following result.

Proposition 2 Increased taxation raises total unemployment, $\partial U^{T O T} / \partial \phi>$ 0 .

Proof. Differentiating equation (13) with respect to $\phi$ gives $\partial U^{T O T} / \partial \phi=$ $\hat{a}\left(u_{c}-u_{e}\right) \partial \hat{a} / \partial \phi$. Hence the result follows from proposition (1) and using that $u_{c}>u_{e}$.

Total unemployment increases with higher tax rates simply because more people choose to acquire education of type $c$ where the unemployment rate is higher. Lower tax rates will thus reduce total unemployment as it encourages workers to choose an educational type associated with shorter expected unemployment spells.

\section{Welfare}

This section is concerned with welfare analysis. We make use of a utilitarian welfare function, which is obtained by adding all individuals' and firms' steady state flow values of welfare. The social welfare function is written as:

$$
S W=\hat{a} \tilde{W}_{c}+\int_{\hat{a}}^{1} \tilde{W}_{e} d a,
$$

where

$$
\begin{aligned}
& \tilde{W}_{c}=u_{c} r U_{c}+\left(1-u_{c}\right) r E_{c}+\left(1-u_{c}\right) r J_{c}+v_{c} r V_{c} \\
& \tilde{W}_{e}=u_{e} r U_{e}+\left(1-u_{e}\right) r E_{e}+\left(1-u_{e}\right) r J_{e}+v_{e} r V_{e}
\end{aligned}
$$

The government budget restriction is

$\left[\hat{a}\left(1-u_{c}\right) w_{c}+(1-\hat{a})\left(1-u_{e}\right) w_{e}\right](t+z)=R$, which can be written in terms of producer wages as:

$$
\left[\hat{a}\left(1-u_{c}\right) \omega_{c}+(1-\hat{a})\left(1-u_{e}\right) \omega_{e}\right](1-1 / \phi)=R .
$$


By making use of the asset equations for workers and firms in the two sectors, equations (1)-(6), imposing the flow equilibrium conditions, ${ }^{6}$ as well as the government budget restriction in (17), and considering the case of no discounting, i.e., $r \rightarrow 0$, we can write the welfare function as follows:

$$
S W=W_{c} \hat{a}+\int_{\hat{a}}^{1} W_{e} d a,
$$

where

$$
\begin{aligned}
& W_{c}=\left(1-u_{c}\right) y_{c}-u_{c} \theta_{c} k+d, \\
& W_{e}=\left(1-u_{e}\right) y_{e}-u_{e} \theta_{e} k-\kappa(a) .
\end{aligned}
$$

Welfare increases in employment and productivity and decreases in vacancy costs. Furthermore, the consumption value tends to increase welfare whereas educational costs tend to reduce welfare. With the assumption of risk neutral individuals, we ignore distributional issues and hence wages will not feature in the welfare function.

As is clear from (18), (19), and (20), the proportional tax rate can only affect welfare through its impact on the allocation of workers across the two educational types. The following condition determines the optimal allocation of workers across the two types of education:

$$
\frac{\partial S W}{\partial(1-\hat{a})}=W_{e}\left(\hat{a}^{*}\right)-W_{c}=\left(1-u_{e}\right) \omega_{e}-\kappa\left(\hat{a}^{*}\right)-\left(1-u_{c}\right) \omega_{c}-d=0,
$$

where $\hat{a}^{*}$ denotes the socially optimal educational allocation. Welfare raises when more workers acquire education of type $e$ whenever the number of workers with educational direction $e$ are too low from a welfare point of view. Similarly, welfare falls as more workers acquire education of type $e$ when too many workers have education of type $e$ from a welfare perspective. This clearly follows by definition as $S W$ is concave in $(1-\hat{a})$ and reaches its maximum when $\left(1-u_{e}\right) \omega_{e}-\kappa\left(\hat{a}^{*}\right)-\left(1-u_{c}\right) \omega_{c}-d=0$.

Comparing this socially optimal allocation of workers across the two educational types, equation (21), to the market solution given by equation (12) gives the following result.

Proposition 3 The presence of taxation, i.e., $\phi>1$, induces too many workers to choose educational type $c$, and thus too few workers to choose

\footnotetext{
${ }^{6}$ Flow equilibrium implies $s_{j}\left(1-u_{j}\right)=\lambda_{j} u_{j}$ and $q_{j} v_{j}=s_{j}\left(1-u_{j}\right)$.
} 
educational type e. Only when there are no taxation, i.e., $\phi=1$, will the private allocation of workers across the two educational types equal the socially optimal allocation.

Proof. The equation for the private solution for the educational direction, (11) can be written as $\left(\left(1-u_{e}\right) \omega_{e}-\left(1-u_{c}\right) \omega_{c}\right) / \phi-\kappa(\hat{a})-d=0$ by using that $w_{j}(1-t)=\omega_{j} / \phi$. For $\phi>1$, the private solution of $\hat{a}$ induces $\partial S W / \partial(1-\hat{a})>0$, that is, increasing $1-\hat{a}$, would increase welfare. Only when there are no taxation, i.e., $\phi=1$, will the private allocation of workers across the two educational types equal the socially optimal allocation, i.e., $\hat{a}=\hat{a}^{*}$.

By comparing the equation for the market allocation of workers across the two types, it is clear that the proportional tax system distorts the individuals' educational choices. Too few workers will choose the educational direction which is associated with effort and too many workers will choose the educational direction which is associated with a positive consumption value.

When the government has a positive revenue requirement, $R>0$, and the government can only attain these with proportional tax rates, those should be chosen as low as possible on order to minimize the distortion in the educational allocation. Thus the tax rates should be set such that: $(t+z)=R /\left[\hat{a}\left(1-u_{c}\right) w_{c}+(1-\hat{a})\left(1-u_{e}\right) w_{e}\right]$. The higher the government revenue requirement, the higher the tax rates and the more inefficient will the educational allocation be, and the lower will welfare be. See the appendix for the formal set-up of the welfare maximization problem.

The inefficiently low number of workers that choose education of type $e$ in the private solution in presence of proportional uniform taxation could however be corrected by the use of other policy instruments. Potential policy instruments are sector specific payroll tax rates, differentiated tuition fees and subsidies. These policy instruments are considered in turn in the following two sections.

\section{Differentiated tax rates}

In this section we consider the option of using differentiated tax rates instead of a uniform income tax. That is, we may have that the tax wedges are different in sector $c$ and $e$, denoted as $\phi_{c} \neq \phi_{e}$ due to either $t_{c} \neq t_{e}$ or $z_{c} \neq$ 
$z_{e}$ or both. Introducing sector specific proportional taxation implies that we allow the tax rates in the value functions to differ. The equilibrium expressions derived from the first order condition from the wage bargains now take the form $(\beta /(1-\beta)) J_{j} / \phi_{j}=E_{j}-U_{j}$ where $\phi_{j}=\left(1+z_{j}\right) /\left(1-t_{j}\right)$. As we know from standard theory of imperfectly competitive labour markets, proportional tax rates will not influence producer wages and the unemployment rate. $^{7}$ This holds also here, inducing that equations (7), (8) and (9) again pin down the producer wage, tightness, and the unemployment rate for each of the two sectors depending on the same exact parameter specification.

However, the consumer wages are affected by the tax rates, $w_{j}\left(1-t_{j}\right)=$ $\omega_{j} / \phi_{j}$, which implies that also the allocation of workers across the two educational directions is affected. We can now write the equation determining the educational allocation as:

$$
\kappa(\hat{a})=\frac{\beta}{1-\beta} k\left(\frac{\theta_{e}}{\phi_{e}}-\frac{\theta_{c}}{\phi_{c}}\right)-d .
$$

Hence, changes in the sector specific tax rates affect the allocation of workers across the education types. We can summarize the impact of differentiated taxation on the allocation of workers and on total unemployment in the following proposition

Proposition 4 An increase in the taxation of workers in sector c, i.e., a higher $\phi_{c}$, or a reduction in the taxation of workers in sector e, i.e., a lower $\phi_{e}$, induces less individuals to choose education of type $c$ and more individuals to choose education of type e. The total number of unemployed workers fall.

Proof. As $\theta_{c}$ and $\theta_{e}$ are determined by (8) independently of the tax rates, we can from equation (22) derive $\partial \hat{a} / \partial \phi_{c}<0$ and $\partial \hat{a} / \partial \phi_{e}>0$. Differentiating equation (13) with respect to $\phi_{c}$ and $\phi_{e}$, respectively, gives $\frac{\partial U^{T O T}}{\partial \phi_{c}}=\left(u_{c}-u_{e}\right) \frac{\partial \hat{a}}{\partial \phi_{c}}<0, \frac{\partial U^{T O T}}{\partial \phi_{e}}=\left(u_{c}-u_{e}\right) \frac{\partial \hat{a}}{\partial \phi_{e}}>0$.

Increasing the relative taxation on workers with an education associated with a positive consumption value makes it less attractive to choose this type of education. Some workers thus find it optimal to reallocate their educational choice towards the educational type $e$, although this educational type is associated with effort costs. As a larger fraction of the work force choose an education which is associated with shorter expected unemployment spells, total unemployment falls.

\footnotetext{
${ }^{7}$ See, for example, Pissarides 1998.
} 
Above we showed that differentiated tax rates affect the individuals' choices of educational type. Now let us consider whether or not it is optimal to impose differentiated tax rates from a welfare perspective. The government budget restriction can now be written:

$$
\hat{a}\left(1-u_{c}\right) \omega_{c}\left(1-1 / \phi_{c}\right)+(1-\hat{a})\left(1-u_{e}\right) \omega_{e}\left(1-1 / \phi_{e}\right)=R .
$$

Following the procedure set out before, it follows that the welfare function again can be represented by equations (18)-(20). The only difference is that the marginal worker who is indifferent between the two types of education, $\hat{a}$, is now given by $(22)$.

Thus we can derive the optimal degree of tax differentiation by maximizing the social welfare function given in (18)-(20) subject to the government budget constraint (23) and the educational allocation of workers (22). Lower tax rates in one sector can now be used to finance higher tax rates in the other sector. As the tax rates also in the case of differentiated tax rates affect welfare only through the allocation of educational types, the optimal design of tax policy follows by a direct comparison of the socially optimal allocation of workers across the two educational types with the private allocation. The question then emerges if the revenue requirement can be reaped while at the same time differentiated tax rates can be used to correct for the fact that proportional uniform tax rates tends to induce too many workers to choose educational type $c$. The result is given in the following proposition.

Proposition 5 The optimal tax policy implies relatively higher tax rates in sector $c$, such that the socially optimal allocation of workers across the two educational types is attained. The optimal tax wedges are given by $\phi_{c}^{*}=$ $\frac{\left(1-u_{c}\right) \omega_{c}}{\left(1-u_{c}\right) \omega_{c}-R}$ and $\phi_{e}^{*}=\frac{\left(1-u_{e}\right) \omega_{e}}{\left(1-u_{e}\right) \omega_{e}-R}$, where $\phi_{c}^{*}>\phi_{e}^{*}$.

Corollary. The optimal tax differentiation between the two sectors increases in the size of the government revenue requirement, $\frac{\partial\left(\phi_{c}^{*}-\phi_{e}^{*}\right)}{\partial R}>0$.

The proof is given in the appendix.

As argued above, uniform proportional taxation induces too many workers to choose an educational type with a positive consumption value, and too few workers choose an educational type with effort costs. It is optimal for the government to correct for this distortion by imposing differentiated tax rates, such that the educational type with a positive consumption value faces a higher tax rate. The optimal degree of tax differentiation increases in the government revenue requirement. As was clear from the previous section, 
the welfare loss due to tax induced distortions to the individual's educational choice is larger the higher the tax rates. A higher degree of tax differentiation is then required to counteract the larger distortion that follows from high government revenue requirements. ${ }^{8}$

\section{$5 \quad$ Differentiated subsidies and tuition fees}

This section considers the impact of tuition fees and subsidies on the choice of educational direction, unemployment, and welfare. First, we introduce tuition fees which are denoted $g_{j}, j=c, e$. Uniform tuition fees correspond to the case $g_{c}=g_{e}$. For simplicity we introduce tuition fees for educational type $c$ by redefining $d$ as $d=\bar{d}-g_{c}$ where $\bar{d}$ is redefined as the positive consumption value of education of type $c$. Analogously, tuition fees for educational type $e$ is introduced by replacing the individual specific costs of education of type $e$ with $\kappa(a)+g_{e}$.

Although these tuition fees are imputed into the equations as flow values, the interpretations could either be that the tuition fees are paid back as annuities or paid only during the time in education. This follows as a model where people continuously are being born and dying generate the same qualitative results.

Equivalently to the previous analysis, the tuition fees $g_{c}$ and $g_{e}$ do not enter into the equations determining tightness, unemployment rate, and producer wages. This holds as they are state independent. The tuition fees do however affect the choice of educational direction. The condition determining the individuals' educational choices is now given by

$$
\kappa(\hat{a})=\frac{\beta}{1-\beta} \frac{k}{\phi}\left(\theta_{e}-\theta_{c}\right)+\left(g_{c}-g_{e}\right)-\bar{d} .
$$

We can summarize the impact of tuition fees on the allocation of workers across the two educational types and on total unemployment in the following proposition:

\footnotetext{
${ }^{8}$ One can note that the optimal policy design given by proposition 5 is independent of the Hosios condition. This follows intuitively from the fact that tightness and unemployment is unaffected by the tax rates. If the Hosios condition does not hold, that is $\eta \neq \beta$, the private outcomes induce an inefficient number of unemployed workers in each sector. This inefficiency can however not be corrected for by use of the tax instruments as these have no impact on the unemployment rates. Thus the optimal tax policy is determined independently of the Hosios condition.
} 
Proposition 6 An increased tuition fee for individuals who acquire education c, i.e., a higher $g_{c}$, or a reduction in the tuition fee for individuals who acquire education e, i.e., a lower $g_{e}$, induces less individuals to choose type $c$ education and more individuals to choose type e education. The total number of unemployed workers fall. With uniform tuition fees, $g_{c}=g_{e}$, general changes in the tuition fees have no impact on educational allocation and the number of unemployed workers.

Proof. As $\theta_{c}$ and $\theta_{e}$ are determined by equation (8) which is independent of the tax rates, from equation (24) we derive $\partial \hat{a} / \partial g_{c}<0$ and $\partial \hat{a} / \partial g_{e}>0$. Differentiating equation (13) with respect to $g_{c}$ and $g_{e}$ gives $\partial U^{T O T} / \partial g_{c}=$ $\left(u_{c}-u_{e}\right) \partial \hat{a} / \partial g_{c}<0, \partial U^{T O T} / \partial g_{e}=\left(u_{c}-u_{e}\right) \partial \hat{a} / \partial g_{e}>0$.

Acquiring education $c$ becomes relatively less attractive when tuition fees for type $c$ education increase or tuition fees for type $e$ education fall. This induces more people to choose education of type $e$, which clearly reduces total unemployment as people reallocate towards the sector where the unemployment rate is lower.

Finally, optimal tuition fees are considered. Following the same procedure as in Section 3 and using the government budget restriction $\hat{a} g_{c}+(1-\hat{a}) g_{e}+$ $\left[\hat{a}\left(1-u_{c}\right) \omega_{c}+(1-\hat{a})\left(1-u_{e}\right) \omega_{e}\right](1-1 / \phi)=R$ provide us with the welfare function in (18)-(20) with the small modification that equation (19) is rewritten as $W_{c}=\left(1-u_{c}\right) y_{c}-u_{c} \theta_{c} k+\bar{d}$. Not very surprisingly we find that:

Proposition 7 In case $\phi>1$, the optimal tuition design involves higher tuition fees for workers who acquire education type c relative to workers who acquire education type e. The optimal solution of tuition fees are then $\left(g_{c}-g_{e}\right)^{*}=\left(\left(1-u_{e}\right) \omega_{e}-\left(1-u_{c}\right) \omega_{c}\right)(1-1 / \phi)>0$ and implies that the socially optimal educational allocation is attained. In case $\phi=1$, and the government instead uses tuition fees to retain the revenue requirement, $R>0$, it is optimal to use uniform tuition fees: $\left(g_{c}-g_{e}\right)^{*}=0$.

The Proof is given in the Appendix.

The distortion created by the untaxed consumption values and effort costs may be corrected for by letting the tuition fees for type $c$ education exceed the tuition fee for type $e$ education. The socially optimal allocation can therefore be implemented by letting $g_{c}>g_{e}$. However, the presence of tuition fees in this simple setting provides an alternative instrument for financing government expenditures. Thus the socially optimal allocation of educational types can also be reached by having no taxes and uniform tuition fees. 
Figure 1: Tax pressure and share of graduates in humanities in various OECD countries.

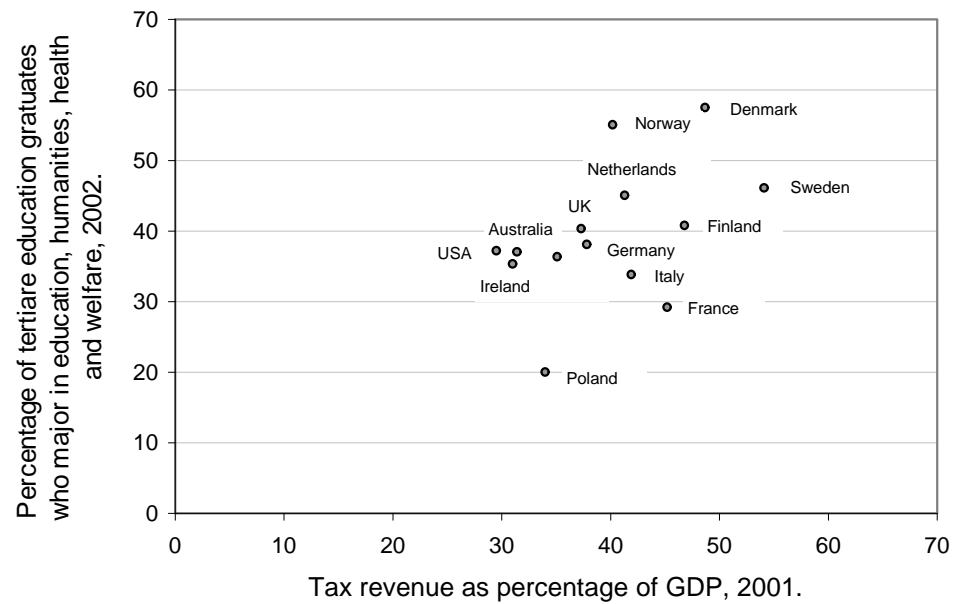

A similar analysis may be carried out if we assume that the government can choose to subsidize one type of education. Not surprisingly, we find that it is optimal for the government to subsidize educations that requires larger effort. Such a subsidy simply corrects for the distortion that too many workers tend to choose the educational type which is associated with a positive consumption value.

\section{Discussion}

We have shown in a two-sector equilibrium model that the presence of taxes can distort the individual's educational choice and induce too many individuals to choose the educational type with lower expected wage return. These individuals value the consumption value of this educational type higher than the additional wage return they could have received by choosing the alternative educational type. Taxes reduces the price on the consumption value of education, measured in foregone income by not choosing the alternative investment that generates higher wage return. We also show that this distortion is larger the higher the tax level. 
Data $^{9}$ for the OECD countries is consistent with this view. From Figure 1 we see that there is a positive correlation between the level of taxation in a country (measured as tax revenue as percentage of GDP) and the share of tertiary education graduates who major in education, humanities, health and welfare. These types of higher education often lead to professions that are relatively low paid compared with for instance engineering and science. This is particularly prevalent in the Scandinavian countries, which are egalitarian societies characterized by large public sectors, high tax levels, and full subsidizing of higher education. The individuals' educational choices determine the skill composition of the labour force and thus also the countries' future production possibilities. The individuals have full freedom of choice prior to the education, while there is a certain lock-in effect when the education is completed.

In our model individuals differ in ability, which again determines the nondeductible effort costs of completing type $e$ education. Type $c$ education is characterized by a higher consumption value, which is a tax free return to that type of education. Sector $e$ has lower unemployment and higher wage return than sector $c$. High ability individuals choose educational type $e$, since they have relatively low effort costs of completing this education, such that the higher monetary return to the educational type more than compensates for the foregone consumption value of type $c$ education. Low ability individuals have high effort costs of completing type $e$ education, and they will instead choose type $c$ education and enjoy the higher consumption value of that educational type. Wage taxes reduce the wage return to education while leaving the consumption value of type $c$ education and the effort cost of type $e$ education unchanged. They reduce the overall return to type $e$ education relatively more than the overall return to type $c$ education. This distorts the educational choice of the marginal individuals, inducing too able individuals to choose type $c$ education. As unemployment is higher in sector $c$, this increases total unemployment in the economy and reduces welfare. Differentiated taxation could be used to correct for this distortion. Higher pay-roll taxes in sector $c$ indirectly taxes the consumption value of type $c$ education, inducing less individuals to choose that education, which again reduces unemployment and increases welfare. The same result is reached by introducing differentiated tuition fees with a higher tuition fee on type $c$ education.

\footnotetext{
${ }^{9}$ OECD Education at a Glance, 2004, and OECD Economic Outlook, 2003.
} 
We therefore argue that part of the high concentration of graduates in humanities in countries like the Scandinavian could be tax induced, and it may be important to correct for this distortion in order to secure an optimal skill combination of the future labour force. One way to correct for this is to induce sector specific tax rates, such that professions that apply humanities graduates are taxed at a higher tax rate. This would reduce the wage return to humanities further, inducing some individuals to switch to other types of education. However, this may not be a politically feasible solution, since it would imply implementation of higher tax rates in lower paid sectors which furthermore are characterized by high unemployment. A more feasible policy tool may be to introduce differentiated tuition fees, where educational types with a high element of consumption requires higher tuition fees, such that individuals pay part of the price of their private educational consumption. Other educational types, where recruitment is low because of a higher required effort to complete it or a relatively low consumption value, can be made more attractive by having low or negative tuition fees. Or equivalent introduce more generous re-payment schemes to student loans taken when acquiring education associated with higher required effort. In this way, the government is able to give strong incentives for the educational types that are important for the countries skill portfolio, but that are less popular among the students.

\section{Conclusion}

Many individuals choose educational directions that offer jobs in sectors with relatively high unemployment and relatively low wages. This is an apparent paradox if one only considers education as an investment that yields higher wages in the future. But by considering higher education both as investment and as consumption, these educational choices become understandable and

rational. Some individuals have such a high consumption value of a particular education that they are willing to forego the future earnings that they could have received by choosing an alternative type of education. The price of the consumption value of their preferred education is the after tax wage increase they forego. High income taxes thus reduce the price on the consumption value of education. One would thus expect that individuals in countries with high taxes and broad welfare states put more emphasis on the consumption value when making their educational choice and less emphasis on the wage 
return. As we saw in the discussion part, we provided some evidence that this may be the case.

We show that this tax induced distortion in the individual's educational choice to some extent can be neutralized by introducing differentiated tax rates or differentiated tuition fees. These tools induce some individuals to choose the alternative educational type with low consumption value and high effort costs in order to enjoy the better future employment possibilities of this education. This reduces total unemployment and increases welfare, and it improves and broadens the aggregated skill portfolio of the country.

Individuals in our framework are heterogenous in the sense that they differ in ability, such that the effort costs of completing the educational type that leads to jobs in the sector with better employment prospects vary across individuals. But they all have the same preferences, such that they have the same valuation of the consumption values of the two types of education. An interesting extension would be to allow individuals to be heterogenous both regarding ability and consumption value of different educational types.

Finally, one can note that this paper only considers the tax induced distortion on the choice of educational type. This focus was a natural departure as we wanted to shed light on a new type of distortion, which, in addition, may become increasingly important in the process of globalization. A natural extension would, however, be to account for that taxes may also distort the choice between attaining higher education or not, as well as the allocation of time between leisure and work, and the allocation between leisure and search.

\section{References}

[1] Alstadsæter, A. (2003): Income Tax, Consumption Value of Education, and the Choice of Educational Type. CESifo Working Paper no. 1055.

[2] Alstadsæter, A. (2004): Measuring the consumption value of education, NHH Discussion Paper SAM 04/2004.

[3] Becker, G.S. (1964): Human Capital. A Theoretical and Empirical Analysis With Special Reference to Education. University of Chicago Press, 3rd edition 1993. 
[4] Boskin, M. (1975): Notes on the tax treatment of human capital. In: U.S. Treasury Department Conference on Tax Research. U.S. Treasury Department, Washington.

[5] Bruce, D. (2000): Effects of the U.S. tax system on transitions into self-employment. Labor Economics 7, 545-574.

[6] Cullen, J. B. and R. H. Gordon (2002): Taxes and Entrepreneurial Activity: Theory and Evidence for the U.S. NBER Working Paper 9015.

[7] Driffil, E. J. and H. S. Rosen (1983): Taxation and Excess Burden: A Life Cycle Perspective. International Economic Review 24(3), 671-683.

[8] Gentry, Willian M. and R. Glenn Hubbard (2000): Tax Policy and Entrepreneurial Entry. American Economic Association Papers and Proceedings 90(2), 283-287.

[9] Heckman, J.J. (1976): A Life-cycle model of earnings, learning, and consumption. Journal of Political Economy 84 (4), pt. 2, 11-44.

[10] Malchow-Møller, N. and J. Rose Skaksen, 2003: How to Finance Education - Taxes or Tuition Fees? CEBR Working paper 2003-28.

[11] Marshall, A. (1920): Principles of Economics, 8th ed. Macmillian, London.

[12] Nielsen, S.B. and P.B. Sørensen (1997): On the optimality of the Nordic system of dual income taxation. Journal of Public Economics 63, 311329.

[13] OECD: Economic outlook 2003.

[14] OECD: Education at a glance 2004.

[15] Parker, S. C. (1996): A time series model of self-employment under uncertainty. Economica 63, 459-75.

[16] Pestieau, P. and U.M. Possen (1991): Tax evasion and occupational choice. Journal of Public Economics 45, 107-125.

[17] Pissarides C (2000): Equilibrium Unemployment theory, Cambridge, MIT Press. 
[18] Pissarides C (1998), The impact of employment tax cuts on unemployment and wages: The role of unemployment benefits and tax structure, European Economic Review 42, 155-83.

[19] Schultz, T.W. (1960): Capital Formation by Education. Journal of Political Economy 68, 571-582.

[20] Walker, I. and Y. Zhu (2003): Eduaction, Earnings and Productivity: Recent UK Evidence. Labour Market Trends, UK National Statistics, March, 145-152. 


\subsection{Appendix}

The assumption of uniformely distribution of ability, $a$, imposes no loss of generality. Suppose that $\widetilde{\kappa}(\widetilde{a})$ is an effort function where $\widetilde{a}$ is distributed according to the cumulative distribution function $F$. Let $a=F(\widetilde{a})$, and define $\kappa(a)$ as $\kappa(a)=\widetilde{\kappa}\left(F^{-1}(a)\right)$. Since $F(\widetilde{a})$ is uniformely distributed, it follows that $\widetilde{\kappa}(\widetilde{a})=\kappa(a)$.

The formal set-up of the welfare maximization problem: Considering the optimal tax level, the formal set-up of the welfare maximization problem is: $\operatorname{Max}_{\phi} S W$ given by (18), (19), and (20) subject to the government budget restriction (17). With a positive revenue requirement, $R>0$, we have $(t+z) \geq R /\left[\hat{a}\left(1-u_{c}\right) w_{c}+(1-\hat{a})\left(1-u_{e}\right) w_{e}\right]>0$. Then $d S W / d \phi=$ $d S W / d \hat{a} \cdot d \hat{a} / \partial \phi<0$. Thus the budget restriction must be binding in case the only available tax instrument is proportional uniform taxation. Thus the optimal tax rates satisfy: $(t+z)=R /\left[\hat{a}\left(1-u_{c}\right) w_{c}+(1-\hat{a})\left(1-u_{e}\right) w_{e}\right]$, where $\hat{a}$ is the allocation determined by the private solution) given these tax rates. Clearly one can speculate over extreme solutions for the tax rates if the revenue requirement is extremely high. For example, an extremely high tax rate would induce all individuals to choose educational direction $c$. The educational choice is then solely based on the access to a positive consumption value of educational type $c$.

Proof of proposition 5 and the corollary. Maximize the social welfare function in (18)-(20) with respect to $\phi_{c}$ given that $\phi_{e}$ is implicitly defined as a function of $\phi_{c}$, i.e., $\phi_{e}=f\left(\phi_{c}\right)$, from the government budget restriction in (23). The following solution defining a relationship between the two tax wedges, $\frac{1-1 / \phi_{c}}{1-1 / \phi_{e}}=\frac{\left(1-u_{e}\right) \omega_{e}}{\left(1-u_{c}\right) \omega_{c}}$, provides a maximum point of the welfare function; i.e., $\partial S W / \partial \phi_{c}=\partial S W / \partial \hat{a} \cdot \partial \hat{a} / \partial \phi_{c}=0$ and $\partial^{2} S W / \partial \phi_{c}^{2}<0$. This solution also assures that the government budget restriction is fulfilled. Substitute the welfare maximizing relationship between the sectorial tax wedges, $1-1 / \phi_{c}=\frac{\left(1-u_{e}\right) \omega_{e}}{\left(1-u_{c}\right) \omega_{c}}\left(1-1 / \phi_{e}\right)$, into the government budget restriction (23) and the budget restriction takes the simple form $\left(1-u_{e}\right) \omega_{e}\left(1-\frac{1}{\phi_{e}}\right)=R$. From this expression it is clear that the revenue requirement, $R$, can be reaped by the appropriate level of the tax rates, i.e., $\phi_{e}$, given the optimal relationship between the two tax wedges. Solve for $\phi_{e}$ from this expression yields $\phi_{e}^{*}=\frac{\left(1-u_{e}\right) \omega_{e}}{\left(1-u_{e}\right) \omega_{e}-R}$, which is substituted into the expression 
for the optimal relation which yields $\phi_{c}^{*}=\frac{\left(1-u_{c}\right) \omega_{c}}{\left(1-u_{c}\right) \omega_{c}-R}$. Substitute these socially optimal tax rates into the private outcome of educational allocation, equation (22), and it follows that $\hat{a}=\hat{a}^{*}$. From proposition 5 we find that $\frac{\partial\left(\phi_{c}^{*}-\phi_{e}^{*}\right)}{\partial R}=\frac{\phi_{c}^{*}}{\left(1-u_{c}\right) \omega_{c}-R}-\frac{\phi_{e}^{*}}{\left(1-u_{e}\right) \omega_{e}-R}$. We know that $\phi_{c}^{*}>\phi_{e}^{*}, \omega_{c}<\omega_{e}$, and $u_{c}>u_{e}$. It then follows that $\frac{\partial\left(\phi_{c}^{*}-\phi_{e}^{*}\right)}{\partial R}>0$ as long as $\left(1-u_{c}\right) \omega_{c}>R$.

Proof of proposition 7. Maximize the social welfare function in (18)(20) with respect to $g_{c}$ given that $g_{e}$ is implicitly defined as a function of $g_{c}$, i.e., $g_{e}=h\left(g_{c}\right)$, from the government budget restriction $\hat{a} g_{c}+(1-\hat{a}) g_{e}+$ $\left[\hat{a}\left(1-u_{c}\right) \omega_{c}+(1-\hat{a})\left(1-u_{e}\right) \omega_{e}\right](1-1 / \phi)=R$. The solution of the relationship between $g_{c}$ and $g_{e},\left(g_{c}-g_{e}\right)^{*}=\left(\left(1-u_{e}\right) \omega_{e}-\left(1-u_{c}\right) \omega_{c}\right)(1-1 / \phi)$, provides a maximum point of the welfare function; i.e., $\partial S W / \partial g_{c}=\partial S W / \partial \hat{a}$. $\partial \hat{a} / \partial g_{c}=0$ and $\partial^{2} S W / \partial g_{c}^{2}<0$. This relationship induces a socially optimal allocation of educational type in the economy. This can be seen by comparing the equation determining the private allocation, equation (11) rewritten as $\left(1-u_{c}\right) \omega_{c} / \phi+\bar{d}-g_{c}=\left(1-u_{e}\right) \omega_{e} / \phi-\kappa(\hat{a})-g_{e}$ to the social optimal allocation of workers across educational types, equation (21), which is rewritten as $\left(1-u_{e}\right) \omega_{e}-\kappa\left(\hat{a}^{*}\right)-\left(1-u_{c}\right) \omega_{c}-\bar{d}=0$. Substitute the optimal relationship for the tuition fees into the government budget restriction yields: $g_{e}=R-(1-1 / \phi)\left(1-u_{e}\right) \omega_{e}$. For a given level of $\phi>0$, the government revenue can thus be reaped by this choice of $g_{e}$. If $\phi=1$ then the optimal solution is $\left(g_{c}-g_{e}\right)^{*}=0$. The government budget restriction can in this case be written as $\hat{a} g_{c}+(1-\hat{a}) g_{e}=R$, or as $g=R$ making use of that $g_{c}=g_{e}=g$. The uniform tuition fee then works as a lump-sum tax, which in this case is distributed as a lump-sum transfer. 


\section{CESifo Working Paper Series}

(for full list see www.cesifo-group.de)

1561 Carlo Altavilla and Paul De Grauwe, Non-Linearities in the Relation between the Exchange Rate and its Fundamentals, October 2005

1562 Josef Falkinger and Volker Grossmann, Distribution of Natural Resources, Entrepreneurship, and Economic Development: Growth Dynamics with Two Elites, October 2005

$1563 \mathrm{Yu}-\mathrm{Fu}$ Chen and Michael Funke, Product Market Competition, Investment and Employment-Abundant versus Job-Poor Growth: A Real Options Perspective, October 2005

1564 Kai A. Konrad and Dan Kovenock, Equilibrium and Efficiency in the Tug-of-War, October 2005

1565 Joerg Breitung and M. Hashem Pesaran, Unit Roots and Cointegration in Panels, October 2005

1566 Steven Brakman, Harry Garretsen and Marc Schramm, Putting New Economic Geography to the Test: Free-ness of Trade and Agglomeration in the EU Regions, October 2005

1567 Robert Haveman, Karen Holden, Barbara Wolfe and Andrei Romanov, Assessing the Maintenance of Savings Sufficiency Over the First Decade of Retirement, October 2005

1568 Hans Fehr and Christian Habermann, Risk Sharing and Efficiency Implications of Progressive Pension Arrangements, October 2005

1569 Jovan Žamac, Pension Design when Fertility Fluctuates: The Role of Capital Mobility and Education Financing, October 2005

1570 Piotr Wdowinski and Aneta Zglinska-Pietrzak, The Warsaw Stock Exchange Index WIG: Modelling and Forecasting, October 2005

1571 J. Ignacio Conde-Ruiz, Vincenzo Galasso and Paola Profeta, Early Retirement and Social Security: A Long Term Perspective, October 2005

1572 Johannes Binswanger, Risk Management of Pension Systems from the Perspective of Loss Aversion, October 2005

1573 Geir B. Asheim, Wolfgang Buchholz, John M. Hartwick, Tapan Mitra and Cees Withagen, Constant Savings Rates and Quasi-Arithmetic Population Growth under Exhaustible Resource Constraints, October 2005

1574 Christian Hagist, Norbert Klusen, Andreas Plate and Bernd Raffelhueschen, Social Health Insurance - the Major Driver of Unsustainable Fiscal Policy?, October 2005 
1575 Roland Hodler and Kurt Schmidheiny, How Fiscal Decentralization Flattens Progressive Taxes, October 2005

1576 George W. Evans, Seppo Honkapohja and Noah Williams, Generalized Stochastic Gradient Learning, October 2005

1577 Torben M. Andersen, Social Security and Longevity, October 2005

1578 Kai A. Konrad and Stergios Skaperdas, The Market for Protection and the Origin of the State, October 2005

1579 Jan K. Brueckner and Stuart S. Rosenthal, Gentrification and Neighborhood Housing Cycles: Will America's Future Downtowns be Rich?, October 2005

1580 Elke J. Jahn and Wolfgang Ochel, Contracting Out Temporary Help Services in Germany, November 2005

1581 Astri Muren and Sten Nyberg, Young Liberals and Old Conservatives - Inequality, Mobility and Redistribution, November 2005

1582 Volker Nitsch, State Visits and International Trade, November 2005

1583 Alessandra Casella, Thomas Palfrey and Raymond Riezman, Minorities and Storable Votes, November 2005

1584 Sascha O. Becker, Introducing Time-to-Educate in a Job Search Model, November 2005

1585 Christos Kotsogiannis and Robert Schwager, On the Incentives to Experiment in Federations, November 2005

1586 Søren Bo Nielsen, Pascalis Raimondos-Møller and Guttorm Schjelderup, Centralized vs. De-centralized Multinationals and Taxes, November 2005

1587 Jan-Egbert Sturm and Barry Williams, What Determines Differences in Foreign Bank Efficiency? Australian Evidence, November 2005

1588 Steven Brakman and Charles van Marrewijk, Transfers, Non-Traded Goods, and Unemployment: An Analysis of the Keynes - Ohlin Debate, November 2005

1589 Kazuo Ogawa, Elmer Sterken and Ichiro Tokutsu, Bank Control and the Number of Bank Relations of Japanese Firms, November 2005

1590 Bruno Parigi and Loriana Pelizzon, Diversification and Ownership Concentration, November 2005

1591 Claude Crampes, Carole Haritchabalet and Bruno Jullien, Advertising, Competition and Entry in Media Industries, November 2005

1592 Johannes Becker and Clemens Fuest, Optimal Tax Policy when Firms are Internationally Mobile, November 2005 
1593 Jim Malley, Apostolis Philippopoulos and Ulrich Woitek, Electoral Uncertainty, Fiscal Policy and Macroeconomic Fluctuations, November 2005

1594 Assar Lindbeck, Sustainable Social Spending, November 2005

1595 Hartmut Egger and Udo Kreickemeier, International Fragmentation: Boon or Bane for Domestic Employment?, November 2005

1596 Martin Werding, Survivor Benefits and the Gender Tax Gap in Public Pension Schemes: Observations from Germany, November 2005

1597 Petra Geraats, Transparency of Monetary Policy: Theory and Practice, November 2005

1598 Christian Dustman and Francesca Fabbri, Gender and Ethnicity - Married Immigrants in Britain, November 2005

1599 M. Hashem Pesaran and Martin Weale, Survey Expectations, November 2005

1600 Ansgar Belke, Frank Baumgaertner, Friedrich Schneider and Ralph Setzer, The Different Extent of Privatisation Proceeds in EU Countries: A Preliminary Explanation Using a Public Choice Approach, November 2005

1601 Jan K. Brueckner, Fiscal Federalism and Economic Growth, November 2005

1602 Steven Brakman, Harry Garretsen and Charles van Marrewijk, Cross-Border Mergers and Acquisitions: On Revealed Comparative Advantage and Merger Waves, November 2005

1603 Erkki Koskela and Rune Stenbacka, Product Market Competition, Profit Sharing and Equilibrium Unemployment, November 2005

1604 Lutz Hendricks, How Important is Discount Rate Heterogeneity for Wealth Inequality?, November 2005

1605 Kathleen M. Day and Stanley L. Winer, Policy-induced Internal Migration: An Empirical Investigation of the Canadian Case, November 2005

1606 Paul De Grauwe and Cláudia Costa Storti, Is Monetary Policy in the Eurozone less Effective than in the US?, November 2005

1607 Per Engström and Bertil Holmlund, Worker Absenteeism in Search Equilibrium, November 2005

1608 Daniele Checchi and Cecilia García-Peñalosa, Labour Market Institutions and the Personal Distribution of Income in the OECD, November 2005

1609 Kai A. Konrad and Wolfgang Leininger, The Generalized Stackelberg Equilibrium of the All-Pay Auction with Complete Information, November 2005 
1610 Monika Buetler and Federica Teppa, Should you Take a Lump-Sum or Annuitize? Results from Swiss Pension Funds, November 2005

1611 Alexander W. Cappelen, Astri D. Hole, Erik Ø. Sørensen and Bertil Tungodden, The Pluralism of Fairness Ideals: An Experimental Approach, December 2005

1612 Jack Mintz and Alfons J. Weichenrieder, Taxation and the Financial Structure of German Outbound FDI, December 2005

1613 Rosanne Altshuler and Harry Grubert, The Three Parties in the Race to the Bottom: Host Governments, Home Governments and Multinational Companies, December 2005

1614 Chi-Yung (Eric) Ng and John Whalley, Visas and Work Permits: Possible Global Negotiating Initiatives, December 2005

1615 Jon H. Fiva, New Evidence on Fiscal Decentralization and the Size of Government, December 2005

1616 Andzelika Lorentowicz, Dalia Marin and Alexander Raubold, Is Human Capital Losing from Outsourcing? Evidence for Austria and Poland, December 2005

1617 Aleksander Berentsen, Gabriele Camera and Christopher Waller, Money, Credit and Banking, December 2005

1618 Egil Matsen, Tommy Sveen and Ragnar Torvik, Savers, Spenders and Fiscal Policy in a Small Open Economy, December 2005

1619 Laszlo Goerke and Markus Pannenberg, Severance Pay and the Shadow of the Law: Evidence for West Germany, December 2005

1620 Michael Hoel, Concerns for Equity and the Optimal Co-Payments for Publicly Provided Health Care, December 2005

1621 Edward Castronova, On the Research Value of Large Games: Natural Experiments in Norrath and Camelot, December 2005

1622 Annette Alstadsæter, Ann-Sofie Kolm and Birthe Larsen, Tax Effects, Search Unemployment, and the Choice of Educational Type, December 2005 